\title{
EXTRACTING PRECISE AND AFFORDABLE DEMS DESPITE OF THE CLOUDS. AJAX: THE JOINING OF RADAR AND OPTICAL STRENGTHS
}

\author{
L.Cunin $^{\mathrm{a}}$, P.Nonin ${ }^{\mathrm{b}}$, J. Janoth ${ }^{\mathrm{c}}$, M.Bernard ${ }^{\mathrm{d} *}$ \\ ${ }^{a}$ IGN Espace, 6 avenue de l'Europe, 31520 Ramonville Saint Agne, France. Laurent.Cunin@ign.fr \\ b ASTRIUM ASV GEO, 2600 Route des Crêtes , 06905 Sophia Antipolis Cedex, France. Philippe.Nonin@ spotimage.fr \\ c ASTRIUM ASV GEO Infoterra, D-88039 Friedrichshafen, Germany. Juergen.Janoth@astrium.eads.net \\ *d ASTRIUM ASV GEO, 5 rue des Satellites, BP14359, 31030 Toulouse, France. Marc.Bernard@ spotimage.fr
}

\author{
Commission IV, WG IV/6
}

KEY WORDS: Radar, SPOT, DEM/DTM, Fusion, Precision, Three-dimensional, Quality, Cost

\begin{abstract}
:
On the one hand, onboard SPOT 5, the HRS instrument systematically collects stereopairs around the Globe since 2002. Each stereopair can encompass an area up to $600 \mathrm{~km}$ x $120 \mathrm{~km}$ within a single pass (i.e. $72000 \mathrm{~km}^{2}$ stereoscopic strips). Covering now more than 120 millions sq.km of the Earth landmasses, SPOT 5 stereoscopic imagery has become one of main satellite data sources for accurate DEM extraction, at least where the cloud coverage leaves a chance to do so !

On the other hand, the TerraSAR-X satellite, launched in June 2007, is able to collect radar data through the clouds in several modes. An approach to extract height information by radargrammetry was developed, and the commercial distribution of Digital Elevation Models based on TerraSAR-X StripMap and SpotLight Modes (resp. 3m and 1m resolution) has started in 2010. To improve the overall height accuracy of the DEM, acquisitions from both orbit directions are utilised, each point on the ground being thus imaged at least 4 times by TerraSAR-X.
\end{abstract}

Since 2002, Spot Image and French National Cartographic Institute (IGN) are building a worldwide database called Elevation30/Reference3D ${ }^{\mathrm{TM}}$, which includes a Digital Elevation Model at 1-arc-second resolution (DTED level 2) extracted from HRS stereopairs.

To answer the wide demand of precise DEMs over Tropical and Northern areas, frequently covered by clouds, a study was performed to integrate StripMap radargrammetric TerraSAR-X data into the Reference3D process, and two prototype products were issued, over Colombia and Congo areas. During this experiment, efforts have been made to stick to technical steps that could be integrated within a standardized production process, in order to keep offering affordable prices while maintaining a high standard of horizontal and vertical accuracy.

The DEMs extracted from TerraSAR-X and HRS proved extremely consistent with each other, showing a mean difference of $0.80 \mathrm{~m}$. This allows to propose a unified Elevation 30 product to the users, with a guaranteed accuracy materialized into the product through a dedicated vertical Accuracy Commitment Mask.

\section{INTRODUCTION}

On the one hand, onboard SPOT 5, the HRS instrument systematically collects stereopairs around the Globe since 2002. Each stereopair encompasses an area up to $600 \mathrm{~km} \mathrm{x} 120 \mathrm{~km}$ within a single pass (i.e. $72000 \mathrm{~km}^{2}$ stereoscopic strips). Covering now more than 120 million sq.km of the Earth landmasses, SPOT 5 stereoscopic imagery has become one of main satellite data sources for accurate DEM extraction, at least where the cloud coverage leaves a chance to do so !

On the other hand, the TerraSAR-X satellite, launched in June 2007 , is able to collect radar data through the clouds in several modes. An approach to extract height information by radargrammetry was developed, and the commercial distribution of Digital Elevation Models based on TerraSAR-X started in 2010.

Since 2002, Spot Image and French National Cartographic Institute (IGN) are building a worldwide database called
Elevation30/Reference3D ${ }^{\mathrm{TM}}$, which includes a Digital Elevation Model at 1-arc-second resolution (DTED level 2) extracted from HRS stereopairs.

To answer the wide demand of precise DEMs over Tropical and Northern areas, frequently covered by clouds, a study was performed to integrate StripMap radargrammetric TerraSAR-X data into the Reference $3 \mathrm{D}$ process, and two prototype products were issued, over Colombia and Congo areas.

\section{DEM EXTRACTION FROM RADAR AND OPTICAL “-GRAMMETRIC" DATA}

Photogrammetry and radargrammetry principles are well known: both rely upon image matching. Main difficulties to be overcome are respectively: water bodies, shadows (steep mountainsides), poor texture (deserts) and low sun-illumination (high latitudes) for optical imagery, and water bodies, steep slopes and sharp edges (mountain tops), consistency over 
agricultural areas, for radar. Scientific literature offers plenty of brilliant papers about principles and methods to extract DEMs from radar and optical pairs

\subsection{DEM extraction from Optical data}

DEM extraction commonly uses 2 optical satellite images, ie a stereopair, from more or less symmetric incidence angles, and can strongly benefit of the addition of a $3^{\text {rd }}$ image, preferably under a near-vertical incidence, to better render the steep areas and deep valleys ("tristereo mode").

As one knows, the clouds do hinder image collection by optical sensor like SPOT5/HRS. This task requires a careful monitoring and patient re-tasking over reluctant (ie cloudy) areas. And sometimes patience itself is not enough: after 11 years of continuous attempts (2002-2012), some areas of the Equatorial belt remain not feasible, from a DEM-extraction point of view, due to persistent cloud cover. The example of French Guyana $\left(84,000 \mathrm{~km}^{2}\right)$ is self-explaining: since the launch of SPOT 5 in May 2002, more than 2,360 HRS stereopairs have been collected, to achieve only $42 \%$ of a cloud-free coverage, though every place in F. Guyana has been imaged (obviously mainly under clouds) more than 202 times since 2002 !

\subsection{DEM extraction from Radar data}

Meanwhile, radargrammetry needs 4 images over most places, ie one ascending pair plus one descending pair. Only in some cases (over gently hilly areas), one radar pair could be sufficient to achieve a good DEM; however as it remains difficult to predict exactly where this will occur, the collection of radargrammetric TerraSAR-X images systematically plans 2 pairs.

As one knows, the clouds do not hinder the collection of TerraSAR-X images. This opens the way to the collaborative extraction of DEM between optical and radar data: the AJAX project.

\section{AJAX CONCEPT AND REQUIREMENTS}

\subsection{AJAX concept and goals}

AJAX did not aim at re-exploring DEM extraction methodologies from optical and radar - grammetric data, fairly well-known, but rather to experiment the joint use of both optic and radar pairs to provide a single consistent, accurate and affordable DTED2 DEM to complement the Elevation30 product line over Equatorial areas.

Two test $1^{\circ} \times 1^{\circ}$ geocells were chosen to demonstrate the potentialities of this blending: one over Colombia (N07W074) and one over Congo (N02E018). Over these two geocells, the cloud-free HRS (ie optical) coverage was below 50\%, which of course made impossible the extraction of any reliable DEM (within our production flow, a $98 \%$ ratio is considered as a minimum).

This paper will focus on the Colombian prototype, as the results over Congo are very similar.

\subsection{AJAX accuracy requirements}

Being bound to be integrated into the Elevation30 Product range, the AJAX prototype should meet the following accuracy requirements:
- $10 \mathrm{~m}$ LE90 for slopes lower than $20 \%$

- $18 \mathrm{~m}$ LE90 for slopes between 20 and $40 \%$

- $30 \mathrm{~m}$ LE90 for slopes greater than $40 \%$

Since 2002, numerous accuracy assessments of the Elevation30 products from HRS (also known as Reference3D) have been performed at international level by independent users: NGA, European Commission/JRC, ImageONE (Japan)... and many others. All concluded that the product fully met its specifications. [Kay, Winkler et al., 2004] [Yoshino et al., 2008] [Le Hir et al., 2010]

\section{PRODUCTION STEPS}

\subsection{Colombian prototype area - Input data}

The Western part of the $110 \mathrm{~km} \times 110 \mathrm{~km}$ geocell consists in a rather flat plain divided by a large river gently flowing Northwards (see Figure 2). A mountain range with very steep slopes occupies the Eastern part of the geocell. Elevations span from $50 \mathrm{~m}$ to $3,150 \mathrm{~m}$ above sea level.

The following Figures 1 and 2 show the input data that were used to produce a combined DEM.

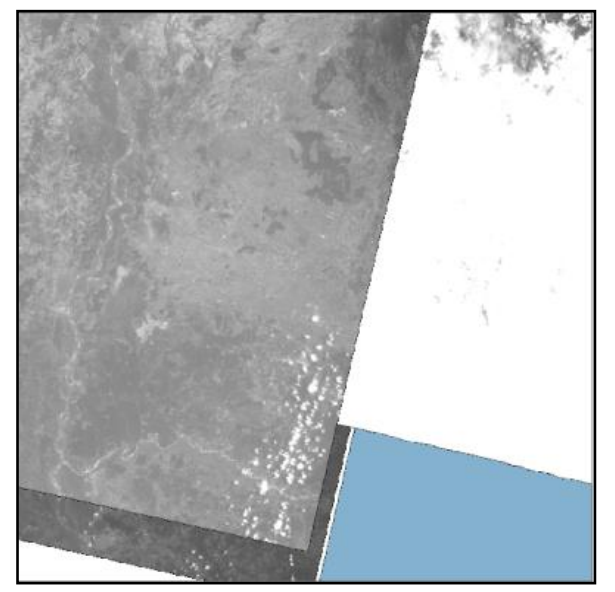

Figure 1 - SPOT 5 HRS coverage over N07W074 Blue and white colours show cloudy areas

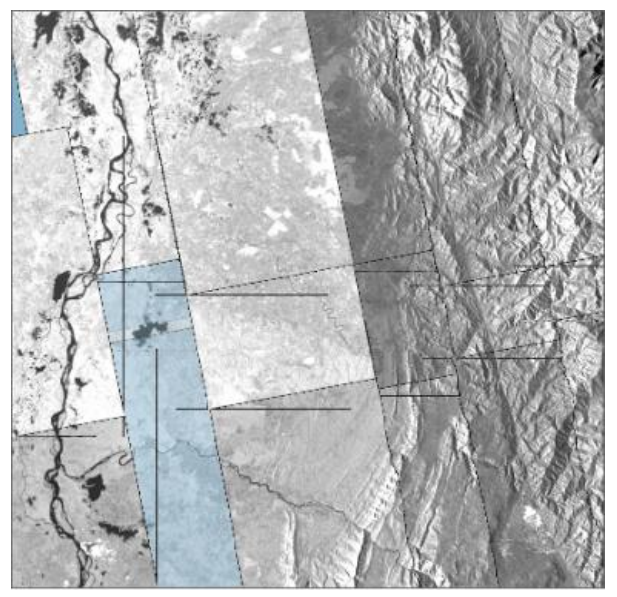

Figure 2 - TerraSAR-X coverage over N07W074 For the purpose of this test, the full geocell was collected by TerraSAR-X, notwithstanding the existing HRS coverage. 


\subsection{Initial production steps}

The first step of the production consists in extracting as much as possible elevation data from optical HRS archive, built over years, and then to determine which areas should be covered by TerraSAR-X data (to be acquired on purpose). This includes the following:

- HRS pairs integration in the continental space-triangulation

- Pair matching - Raw HRS DEM computation

- HRS DEM merging and mosaicking

- Void Mask extraction => determination of TSX area

- Water Mask delineation

Then the missing parts are collected by TerraSAR-X, and the following tasks take place:

- Ascending and descending pairs acquisition on TSX area

- Raw TSX DEM computing (radargrammetry matching)

- Raw TSX DEM merging and mosaicking

- Water Mask delineation (on areas not already covered by HRS Water mask)

These steps were performed in their "standard way" by the staff in charge of DEM production both in Germany for TerraSAR-X, and in Toulouse (France) for SPOT 5 HRS.

\subsection{DEM merging}

After this began a more specific processing chain, directly linked with AJAX:

- Merging of DEMs from HRS and TSX

- Automatic detection of voids and artefacts

- Patching of remaining voids with SRTM) DEM from the Internet (resampled to 1 arc.second)

- Edition Phase

- Water flattening on merged DEM, using the Water Masks previously delineated

- DLD (Double-Line Drains) processing: the rivers are made flowing smoothly downstream

- Final DEM quality control, visual detection of remaining artefacts $=>$ digitisation of uncertified areas ; registering into the corresponding mask

At the end of the day, the resulting AJAX DEM originates in balanced parts from TerraSAR-X and SPOT 5, as shown in Figure 3 below:

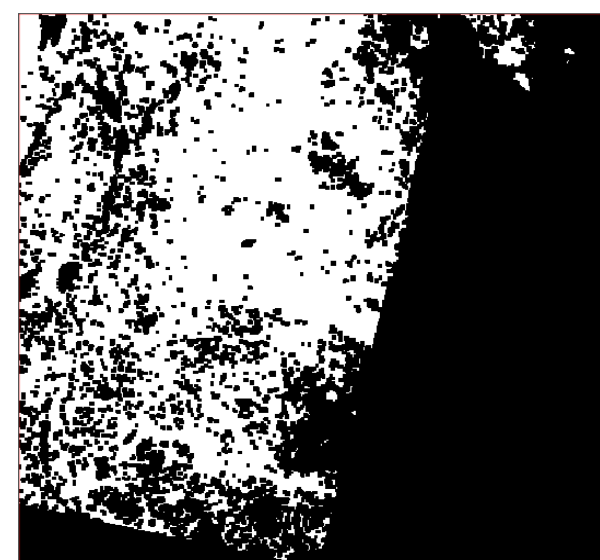

Figure 3 - Sources of the AJAX DEM.

TerraSAR-X is shown in black, SPOT 5 HRS in white.

\section{QUALITY CONTROL AND VALIDATION}

Since the beginning of the production in 2002, Quality Control and Validation steps represent a significant part of the Elevation 30 production flow (15 to $20 \%$ as an average). The merging of radar and optical DEMs of course introduces the necessity of a dedicated $V \& V$ process.

\subsection{Control of the merging}

Indeed, we were very pleased that the two different DEMs, extracted from $100 \%$ independent sources (TerraSAR-X and SPOT 5) by $100 \%$ different and independent teams -though equally skilled and experimented- in Germany and France proved extremely consistent, as demonstrated by the histogram of elevation differences (Figure 4).

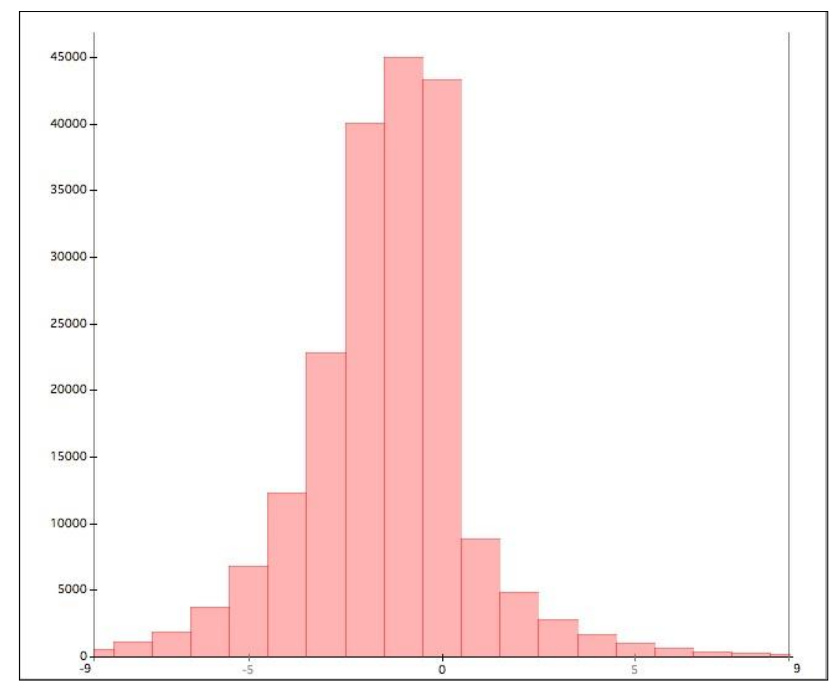

Figure 4 - HRS and TerraSAR-X Elevation differences.

The overall bias between the two DEMs is $0.80 \mathrm{~m}$ (TSX higher than HRS), and more than $90 \%$ of the differences are less or equal to $4 \mathrm{~m}$. Thanks to this excellent result, no unbiasing/ elevation adjustment was applied during the merging process.

\subsection{Absolute validation of the DEM vs ICESAT data}

From Carabajal and Harding (2005), the Geoscience Laser Altimeter System (GLAS) on the Ice, Cloud, and land Elevation Satellite (ICESat) provides a globally-distributed data set well suited for evaluating the vertical accuracy of digital elevation models (DEMs). These authors quote a vertical error of $0.04 \pm$ $0.13 \mathrm{~m}$ per degree of incidence angle. As compared to the Elevation30 accuracy specifications, these figures are small enough to entitle ICESat a perfect data source to assess the AJAX DEM accuracy.

Whatever precise in elevation, the ICESAT measure refers to a near-circular $70 \mathrm{~m}$ spot on the ground, far larger that the AJAX posting interval ( 1 arc.second, ie approx $30 \mathrm{~m}$ in Colombia). Therefore, the first step of the production process is filtering the adequate ICESat dataset to carefully select elevations that can be used with reasonable doubt as "ground truth". The filtering process is based upon the local slope; land cover is not considered. Please refer to Le Hir et al. (2010) for more details on the filtering and selection process of ICESAT data. 
After this selection, only 209 ICESAT "truth points" were kept, only a few dozens of them laying on the Eastern part of the geocell (Figure 5).

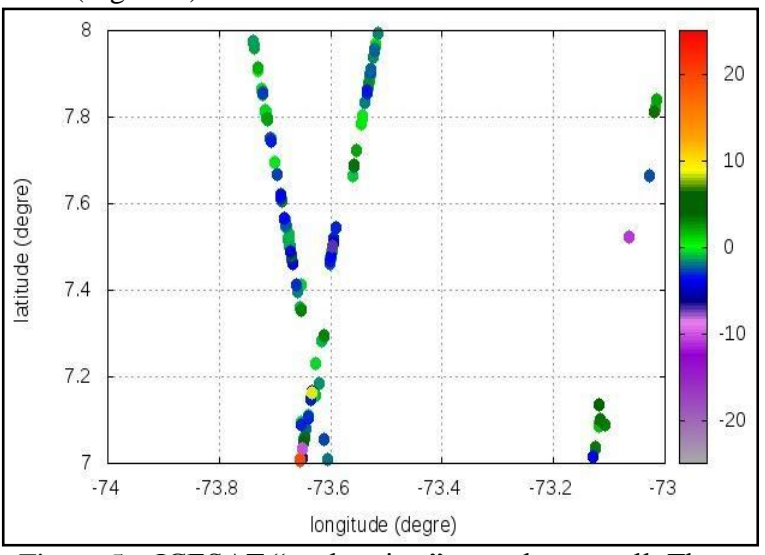

Figure 5 - ICESAT "truth points" over the geocell. Three different orbits can easily be identified. Colours show the magnitude of the elevation difference (in meters) between ICESAT measurements and the AJAX DEM.

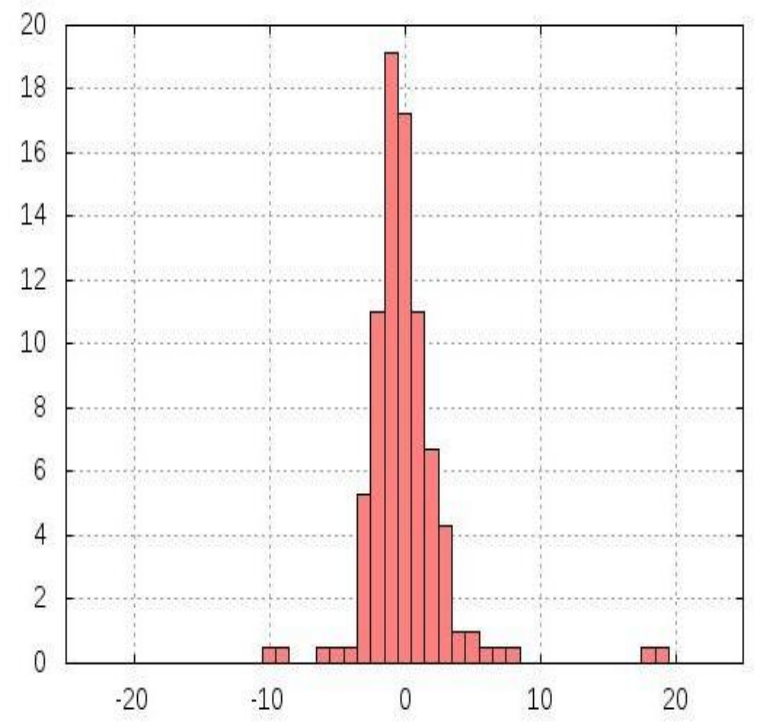

Figure 6 - Histogram (in \%) of the elevation differences against ICESAT (in meters).

The comparison of AJAX DEM against ICESAT measurements gave the following results:

$$
\begin{array}{ll}
\text { - } & \text { Mean }=0.51 \mathrm{~m} \\
\text { - } & \text { Std deviation }=3.1 \mathrm{~m} \\
\text { - } & \text { approx. 5.0m LE90 accuracy. }
\end{array}
$$

\section{3 "Vertical Accuracy Commitment" mask}

As for each and every Elevation30 product, the AJAX prototype also includes a Vertical Accuracy mask which provides for each elevation post the best accuracy commitment from the producer (Figure 7).

The methodology to build this layer is detailed in Le Hir (2010).

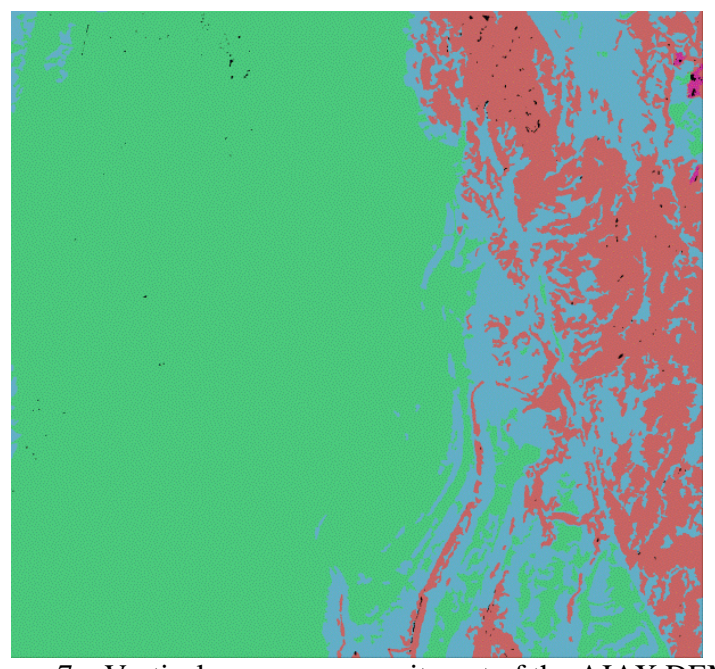

Figure 7 - Vertical accuracy commitment of the AJAX DEM.

As shown in the Figure 7 above, our accuracy commitment ranges from $6 \mathrm{~m}$ LE90 in the flat areas (in green), up to $30 \mathrm{~m}$ LE90 (in pink) over the extreme slopes. Black dots indicate elevation posts for which no commitment could be taken.

\section{CONCLUSION}

A merged DEM was produced over a very "difficult" area in Colombia, through the merging of two independently produced DEMs from TerraSAR-X and SPOT 5 HRS data.

Validation against ICESAT data, as well as the very low differences between both DEMs, show that the resulting accuracy is in line with our Elevation30 requirements. Therefore, detailed commitments can be taken towards the users regarding the vertical accuracy of the resulting DTED level 2 DEM.

\section{References:}

Bouillon et al., 2006, SPOT 5 HRS geometric performances: Using block adjustment as a key issue to improve quality of DEM generation, ISPRS Journal of Photogrammetry \& Remote Sensing 60 (2006) 134-136.

Carabajal, C. C., and D. J. Harding (2005), ICESat validation of SRTM C-band digital elevation models, Geophysical Research Letters, 32, L22S01, doi:10.1029/ 2005GL023957.

Kay, Winkler, 2004, Quality checking of DEM derived from satellite data (SPOT and SRTM), 10th Annual Conference on Control with Remote Sensing of Area-based Subsidies. Budapest, 24-27 November 2004.

Le Hir et al., 2010, Updating and improving the accuracy of a large 3D database..... ISPRS Congress, Kyoto, August 2010, Commission VIII.

Yoshino et al., 2008, Building a consistent geometric frame over Sparse islands using SPOT 5 data, ISPRS Congress, Beijing, August 2008, Commission VII, WG VII/7. 